\title{
Measuring Time Preferences Using Stated Credit Repayment Choices
}

\section{Hanjin $\mathrm{Li}^{1}$ (1) $\cdot$ Danny Campbell ${ }^{1}$ (i) $\cdot$ Seda Erdem ${ }^{1}$ (1)}

Accepted: 29 November 2021 / Published online: 27 January 2022

(c) The Author(s) 2022

\begin{abstract}
This paper explores consumers' repayment decisions and their time preferences. We do this through a hypothetical study using a stated-preference approach. In our experiment, participants are asked to make repayment decisions over time, under different loan sizes. We report five choice trajectories: minimum delay, monotonically decreasing, trajectory with one contradicting choice, trajectory with more than one contradicting choice, and maximum delay. These choice trajectories are taken into account in our modelling approach. Our analysis uses choice models that jointly estimate the discount rate and the probability of choice trajectories. Observed heterogeneity in repayment behaviour is further analysed using sociodemographic factors, and tested for the two loan sizes. We report heterogeneity in consumer repayment decisions, and what happens in the decision-making process for participants in different sociodemographic groups, for different loan sizes. These findings suggest that decision-makers can tailor their strategy for mitigating consumer debts by targeting different groups in the population demonstrating different choice behaviour and decision-making.
\end{abstract}

Keywords Time preference $\cdot$ Repayment decisions $\cdot$ Choice trajectory $\cdot$ Discount rate

Seda Erdem

seda.erdem@stir.ac.uk

Hanjin Li

hanjin.li1@stir.ac.uk

Danny Campbell

danny.campbell@stir.ac.uk

1 Division of Economics, School of Management, University of Stirling, Stirling FK9 5AE, UK 


\section{Introduction}

An increasing variety of short-term loans have been offered to consumers in the United Kingdom (UK) in recent decades. High-cost short-term credit-one type of short-term loan-has received considerable attention from people seeking a loan because of its accessibility (Financial Conduct Authority 2019). Expensive credit costs contribute to over-indebtedness (67\% of payday loan borrowers) and low levels of confidence in managing personal finances (61\% payday loan borrowers) (Financial Conduct Authority 2019). In 2018 consumers borrowed $£ 1.3$ billion, and repaid $£ 2.1$ billion-1.65 times the original loan value. The same phenomenon is also apparent in the credit card market. According to UK credit card statistics (Lilly 2020), monthly credit card spending has increased gradually from $£ 2.92$ billion in 1993 to $£ 15.74$ billion in 2019; an increased volume of transactions has also led to repayment issues among credit consumers. While the amount of money borrowed has increased, there has also been a drop in repayments from 2012; the gap between lending and repayment has increased from $£ 0.4$ billion in 2009 to $£ 4.04$ billion in 2018. Problems with financial credit products have implications not just for credit consumers, but for financial institutions also, which regulators have placed under increased scrutiny to control persistent, unmanageable, consumer debt.

Difficulties in repaying borrowed money can be attributable to various factors, including a consumers' ability to repay. Three repayment behaviours lead to an inability to repay borrowed monies (Financial Conduct Authority 2016): (i) arrearsi.e. consumers who have been charged off or have missed a payment(s); (ii) persistent debt-i.e. consumers with high credit use near debt limits who incur constant interest; and (iii) systematic minimum repayment-i.e. consumers who make only minimum repayments. Although these behaviours in the short term enable borrowers to retain borrowed money for longer, they lead to accumulated debt because of high interest charges. ${ }^{1}$

Repayment behaviour is influenced by how consumers understand and interpret financial terms, such as interest rates. For example, Ponce et al. (2017) reported consumers allocated a higher share of debt to high-interest cards, rather than minimising interest by better debt allocation and paying-off high-interest credit sooner. Gathergood et al. (2019) reported a repayment heuristic, called 'balance-matching', under which consumers aim to match the share of repayments to the share of balances on each credit card when allocating money to repayments. Under this repayment heuristic, minimising interest charges is not the main factor under consideration during repayment allocation. The repayment allocation links to how consumers value their financial situation related to credit debt and how consumers would like to repay the credit debt, whether to pay off debt sooner or later-i.e. 'time preference' (Shui and Ausubel 2004). Delaying repayment-paying back at a later date (rather than sooner) at a higher cost-affects future repayments (Read 2004), rendering these choices 'intertemporal'.

\footnotetext{
1 According to the reported statistics in Financial Conduct Authority (2020), on average consumers who are in persistent debt pay $£ 2.5$ in interest and borrowing costs for every $£ 1$ in loan.
} 
Intertemporal choices are studied in explorations of time preference that affect an individual's life-changing decisions, such as health, education, marriage, wealth and happiness, and for national economic prosperity (Berns et al. 2007; Frederick et al. 2002). Money is a major metric of time preference because it is both easy to measure and socially important (Ericson and Laibson 2019). The most prevalent technique to ascertain an individual's time preference is to ask whether they would prefer a monetary reward sooner or later, also known as the 'money earlier or later (MEL)' method (Cohen et al. 2016). Various question formats for presenting to participants exist, such as the multiple price list (Thaler 1981; Coller and Williams 1999; Harrison et al. 2002; Andersen et al. 2006), double multiple price list (Andersen et al. 2008), matching (Benhabib et al. 2010), and convex time budget (Andreoni and Sprenger 2012).

In conventional multiple price list surveys, individuals make choices in series of questions in which two options are provided-to receive payment $x$ at time $t$, or receive payment $y$ at time $t+k$, where $y>x, k>0$, and where $y$ progressively increases from one question to the next. For example, in a situation where a person is asked if they would prefer $£ 100$ today or $£ 100+z$ tomorrow, theoretically they would choose 'today' if their discount rate is higher than $z \%$. When $z \%$ reaches the discount rate, they should switch to the 'tomorrow' option. Shortcomings of this approach are their inconsistent and anomalous high estimates of discount rates (Frederick et al. 2002). Matching formats also generate extremely high discount rates, under which participants are required to match sooner and later options, e.g., the value $x$ at time $t$ does not differ from value $y$ at time $t+k$. A main factor contributing to anomalously high discount rates is 'present bias', which in the case of a monetary reward a person would prefer to obtain it immediately to avoid any risk of losing it (Hardisty et al. 2013). To accommodate this bias, (Andersen et al. 2008) indicated that risk aversion has impacts on an individuals' time preference, and included 'risk element' into payment options in multiple price lists (referred to as 'double multiple price list'), then jointly estimated time and risk preferences. Using this approach (Andersen et al. 2008) reported significantly lower discount rates than those using a multiple price list approach.

In another format of money allocation experiment, the 'Convex Time Budget' (Andreoni and Sprenger 2012), participants are given a fixed budget in tokens and asked to make a number of payment decisions by allocating tokens to time (token values $\$ 0.10$ to $\$ 0.20$ ) and time $t+k$ (token value $\$ 0.20$ ). Tokens allocated to different time points decide the amount of money a participant would receive. Analysis of this format is based on 'demand theory,' which solves the inequality constraint in multiple and double multiple price list approaches. Although literature regarding time preference and measuring approaches is extensive, discount rate estimates vary across studies, which are affected by other factors, including methods, reward size, time span (between $t$ and $t+k$ ), and type of sample. Andreoni et al. (2015) also maintained that a reliable discount rate is generated from data in related context, specifically that discount rate, estimated using methods that ask participants making decisions on receiving monetary rewards earlier or later, cannot be used as evidence in the context of repayment decisions. 
This paper contributes to the literature in four ways. First, we provide empirical evidence on how to measure time preference in the context of repayment decisions (loss), rather than monetary reward (gain). MEL question-style approaches require an individual to compromise between time and reward. A person would wait a longer time to obtain a higher monetary reward if patient. However, patience impacts credit card repayment decisions less when a person must make a compromise between time (delay duration) and cost (borrowing cost, such as interest charges). People who prefer to repay a loan over a longer term will incur higher borrowing costs. In accordance with the concept of 'loss aversion', people tend to be more sensitive to losses than to gains (Benartzi and Thaler 1995). Because of this, time preference measured in terms of repayment decisions (e.g., individuals make decisions on paying off the loan sooner with lower cost or later with higher cost) differs from MEL cases (e.g., making decisions on receiving less monetary reward sooner or more reward later), and which have not receive much research attention (Coller and Williams 1999; Harrison et al. 2002). Second, we use a novel technique to collect data where time preferences and discount rates in repayment choices are estimated using a 'stated preference elicitation' technique, 'discrete choice experiments (DCE)'. While we cannot observe real-time repayment choices, with our hypothetical setting, we can control experimental set-up and gather a panel of responses to choose scenarios involving different interest rates and repayment terms to simultaneously model choice trajectories and discount rates. Earlier research on repayment behaviour has mainly used marketing data and not drawn attention to time preferences aspect (Lusardi and Tufano 2015; Gathergood et al. 2019). ${ }^{2}$ We contribute a methodology to understand how repayment choice data can be analysed. Our modelling framework explores the heterogeneity of repayment choice trajectories, and estimates choice probability and discount rates conditional on previously identified choice trajectories. Finally, we contribute to knowledge of behavioural aspects of choice and decision-making, and more specifically, explore repayment behaviour and choice trajectories when small and large amounts of money are borrowed.

We request participants choose loan repayment options when borrowing $£ 500$ or $£ 5000$ at different interest rates (borrowing cost) and delay durations. Results indicate that repayment choices differ with an individual's discount rate. Four consumer repayment behaviours are identified: (1) individuals who repay borrowed amounts without delay (minimum delay); (2) individuals who repay borrowed amounts with maximum delay; (3) individuals who make one consistent choice, who repay money quicker when interest rates increase; and (4) individuals who make inconsistent choices, who delay repayments when interest rates (borrowing cost) increases. Our analyses characterise choice trajectories and consumer repayment behaviours based on socio-demographic characteristics. Participants exhibit more consistent repayment choices when the amount borrowed increases.

\footnotetext{
${ }^{2}$ We emphasize that our aim is not to compare different methodologies for eliciting time preferences. While previous studies. e.g., Ventura (2003), used secondary data sources to directly measure time preferences, there is no secondary data available for us to jointly explain choice trajectories and discount rates.
} 
Table 1 Financial literacy questions
Q1. If the inflation rate is $5 \%$ and the interest rate you get on your savings is $3 \%$, will your savings have more, less, or the same amount of buying power in a year's time?

More The same Less Don't know

Q2. High inflation means that the cost of living is increasing.
True
False
Don't know

Q3. It is less likely to lose all of your money if you spread it in multiple investment options.
True
False
Don't know

Q4. A higher annual percentage rate (APR) charge means that there will be a higher interest to pay for the amount borrowed.
True
False
Don't know

Q5. Assume you have a debt of $£ 100$, and you pay back $£ 5$ per month with an annual percentage rate of $20 \%$, how many months do you think it takes to clear your balance?

$$
\begin{aligned}
& \text { Less } 24 \text { months More than } 24 \text { months Don't know } \\
& \text { than } 24 \\
& \text { months }
\end{aligned}
$$

Q6. Suppose you put $£ 100$ into a saving account with an interest rate of $10 \%$ per year. Assuming you don't make any further deposits into this account and you don't withdraw any money. What will be the balance in this account at the end of the first year (after the interest payment is made)?
$£ 105$
$£ 100$
$£ 110$
Don't know

Q7. What will be the balance in this account at the end of two years (after the interest payment is made)?

$£ 105 £ 110 \quad £ 121 \quad$ Don't know

The next section describes the study design of time preference elicitation using stated preference approach and data collection; the following section explains the construction of our model; The next section provides results of discount rate and prediction of repayment behaviours; The following section discuss the results against previous literature; and in the last section a study conclusion is provided.

\section{Study Design and Data}

Our experiment involves a test that measures participant's financial literacy, a series of discrete choice tasks asking how they choose to repay their credit card balances in provided scenarios, and a follow up survey on their demographics.

Participants were given a financial literacy test with questions modified from Frederick et al. (2002) and INFE (2011) that measured their knowledge of interest rates, risks, inflation, numeracy, and capability to calculate compound interests and 
borrowing costs (Table 1). They were also asked standard questions regarding their age, gender, education, income, and working status. ${ }^{3}$

To understand consumer repayment behaviours, we asked participants to state their repayment preferences in a hypothetical experiment that resembled actual credit card debt repayment decisions. A sequence of tasks was designed based on a range of discount rates, each with an option to 'repay $£ x$ with $t$ months delay'. For research validity, our discount rates were within (then) current market ranges. In choice tasks we included more repayment options to give participants greater freedom to choose options between extremes (removing the restriction of a binary choice in conventional techniques).

Experiments are based on common assumptions when modelling time preference: constant discounting behaviours and stationary flow utility function (Cohen et al. 2016). The former is used in multiple price list experiments, and means that the value of a discount function is static if the time $k$ that a person chooses to wait remains the same (the discount function is determined by time $k$ rather than the decision point $t ;{ }^{4}$ ) thus, research of this nature focuses on the term that a person chooses to delay, rather than a decision point. The latter relates refers to the size effect (Thaler 1981), which means that the flow of discounting utility (e.g., the amount of monetary rewards in MEL studies) affects a person's time preference.

Our two treatments investigated whether payment behaviours and time preferences varied with loan size. In treatment 1, participants were asked to make repayment decisions after borrowing $£ 500$, and in treatment $2, £ 5000$. In both treatments participants were asked if they wished to repay a credit balance on time, or be granted an extension of month(s) at cost . Seven scenarios with various interest rates were included that calculated the cost of borrowing each sum of money over a 12 month period. For each scenario the interest rate was fixed, but it varied across scenarios, ranging 5-35\% in 5\% increments (Fig. 1). Presenting scenarios in this way provided participants an opportunity to compare the amount they had to pay with different time delays. The expectation is that quicker repayments would occur at increased interest rates, with the point at which a participant switched a repayment behaviour (repaying earlier or later) enabling identification of their discount rate. (For example, someone with a discount rate of 7\% would opt for any of 13 alternatives in a scenario with a $5 \%$ interest rate, and would choose to 'pay on time' in all other scenarios where the interest rate exceeded $5 \%$ (higher than their $7 \%$ discount rate). However, someone with a discount rate of $17 \%$ would choose any alternative in scenarios with an interest rate of $15 \%$ or less, but to 'pay on time' in scenarios when interest rates exceeded 20\%.) Apart from eliciting a participant's discount rate, simultaneously presenting all scenarios and options in this manner enables choice trajectories of repayment decisions to be observed when interest rates are increased.

\footnotetext{
3 In this paper, we focus only on gender, age, income and financially literacy as these were observed to be play a larger role on choices.

4 This is an unrealistic assumption and provoked discussion a person's preferences do change over time. However, it has been utilised in much research due to the convenience for data collection and analysis. Additionally, stationary discounting behaviour allows economists to have insight into the change of a person's preferences over time (Frederick et al. 2002). This research does not take decision point into account.
} 
Treatment 1

Which repayment option would you prefer the most?

Consider you borrow $£ 500$ from a credible financial institution. You are provided with repayment options for the following seven scenarios. For each scenario, would you prefer to pay back the $£ 500$ on time or pay back the bigger amount at the later stage?

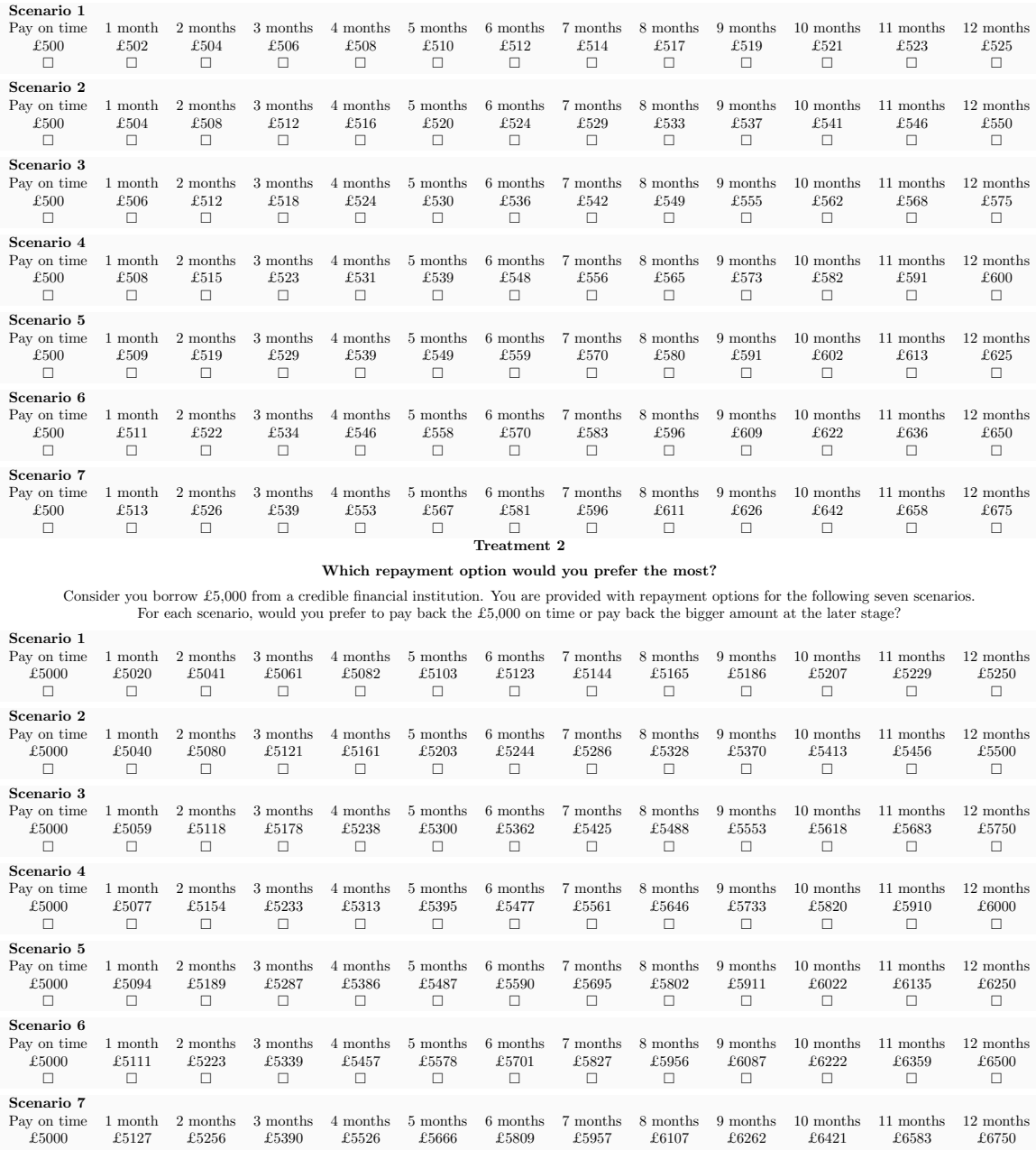

Fig. 1 Example of choice task

Our objective is to see if participants' repayment decisions vary across the choice trajectories.

Data are collected from a nationally representative sample of persons in the UK using an ESOMAR-compliant survey research company. Our sample included 2100 participants over 18 years age, 1050 of which were randomly assigned to each treatment. In each treatment there were slightly more females than males; for treatment $1,17 \%$ of participants were aged 30 or less, $57 \%$ were aged between 31 and 60 years, and $25 \%$ were over 60 years. Treatment 2 included about $9 \%$ more participants (26\%) less than 30 years age, 10\% less in the age range 31-60 years 
Table 2 Breakdown of participants

\begin{tabular}{|c|c|c|c|c|c|c|}
\hline & \multicolumn{2}{|c|}{$\begin{array}{l}\text { Treatment } 1 \\
(N=1045)\end{array}$} & \multicolumn{2}{|c|}{$\begin{array}{l}\text { Treatment } 2 \\
(N=1055)\end{array}$} & \multicolumn{2}{|l|}{ Overall } \\
\hline & Number & Percent & Number & Percent & Number & Percent \\
\hline Female & 548 & 52.44 & 530 & 50.24 & 1078 & 51.33 \\
\hline Male & 497 & 47.56 & 525 & 49.76 & 1022 & 48.67 \\
\hline Aged 18-30 & 182 & 17.42 & 272 & 25.78 & 454 & 21.62 \\
\hline Aged 31-60 & 596 & 57.03 & 492 & 46.64 & 1088 & 51.81 \\
\hline Aged over 60 & 263 & 25.17 & 287 & 27.20 & 550 & 26.19 \\
\hline Income below $£ 15,000$ & 199 & 19.04 & 182 & 17.25 & 381 & 18.14 \\
\hline Income $£ 15,000-£ 29,999$ & 314 & 30.05 & 335 & 31.75 & 649 & 30.90 \\
\hline Income $£ 30,000-£ 39,999$ & 173 & 16.56 & 172 & 16.30 & 345 & 16.43 \\
\hline Income above $£ 40,000$ & 271 & 25.93 & 280 & 26.54 & 551 & 26.24 \\
\hline Income(prefer not to say) & 88 & 8.42 & 86 & 8.15 & 174 & 8.29 \\
\hline Financially literate & 247 & 23.64 & 214 & 20.28 & 461 & 21.95 \\
\hline Financially illiterate & 798 & 76.36 & 841 & 79.72 & 1639 & 78.05 \\
\hline
\end{tabular}

(47\%), and $27 \%$ aged over 60 years (Table 2). There was no significant difference in income between treatments, with about $18 \%$ of participants earning less than $£ 15,000$ in each, with those earning between $£ 15,000$ and $£ 29,999$ representing $30 \%$ of participants, $16 \%$ earning between $£ 29,999$ and $£ 39,999$, and $26 \%$ earning more than $£ 40,000$. In financial tests, $24 \%$ of treatment 1 and $20 \%$ of treatment 2 participants correctly answered all seven financial literacy questions, and are referred to as 'financially literate.'

\section{Empirical Approach}

Recall from Fig. 1 that the interest rate (i.e., borrowing costs) increases across seven choice scenarios and that the time delays were the same in all choice scenarios. Based on normative expectations of choice, individuals would be expected to prefer to pay back a loan sooner as the interest rate increases. Thus, it is expected that as individuals progress from the first to the last choice task, their chosen time delay monotonically decreases (i.e., decreasing or remaining constant, and never increasing). Therefore, as a first step, we examined the choice trajectory for each individual and classified them on the basis of whether or not their sequence of choices are consistent with normative expectations. To illustrate, consider the classification of mutually exclusive trajectories of choice presented in Fig. 2. Both choice trajectories in Fig. 2a are consistent with normative expectations. Specifically, individuals whose discount rate is smaller than the interest rate in the first choice task should always choose the minimum delay (i.e., pay on time), whereas individuals with a discount rate above than the interest rate in the final choice task (in our case 35\%) should always choose the maximum delay (i.e., 12 


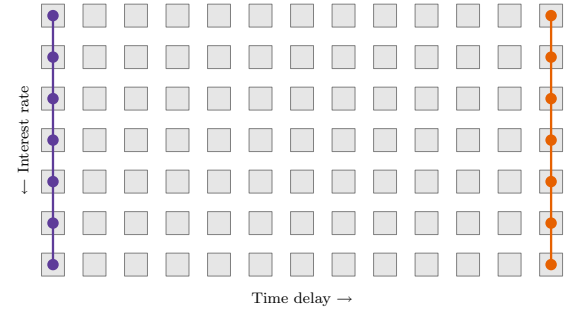

(a) Minimum delay and maximum delay choice trajectories

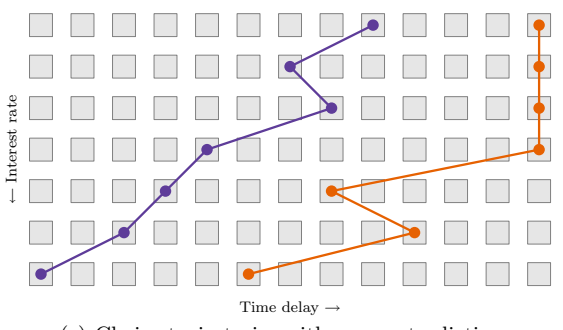

(c) Choice trajectories with one contradiction

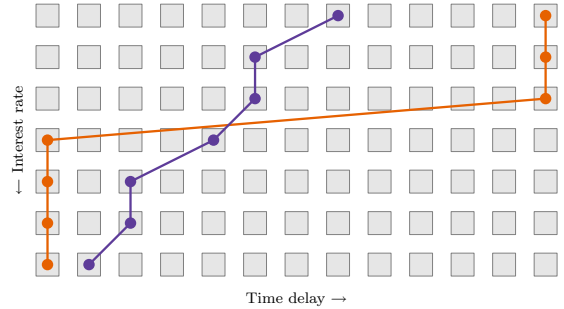

(b) Monotonically decreasing choice trajectories

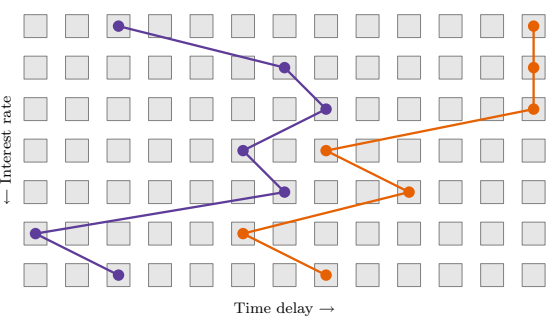

(d) Choice trajectories with more than one contradiction

Fig. 2 Example choice trajectories

months). ${ }^{5}$ For the purposes of this paper, individuals with these choice trajectories are, respectively, classified as having made minimum delay and maximum delay choices. Examples of choice trajectories that monotonically decrease and are not composed of a sequence of minimum delay or maximum delay choices are depicted in Fig. 2b. Strictly speaking, utility maximising individuals should delay paying back the loan for as long as possible whenever the interest rate is less than their discount rate and then switch to paying it back as soon as possible whenever the interest rate exceeds their discount rate. Thus, utility maximisers should only choose the rightmost and leftmost alternatives, as illustrated in one choice trajectory in Fig. 2(b). Only if an individual's discount rate is equivalent (or very close) to the interest rate of a choice task it make sense to choose an intermediate time delay, in which case they would be indifferent and could choose any alternative. Thus, a monotonic decrease does not, on its own, mean that the choice trajectory conforms with theoretical expectations. That said, as departures from monotonicity increase, the support for these expectations decrease. For this reason, while the individuals we classify as exhibiting a monotonically decreasing choice trajectory may not all have made behaviourally consistent choices (as depicted in the other trajectory in Fig. 2c), we can still consider their choices to be at least somewhat consistent compared to individuals who made a contradictory choice, whereby they choose a longer time delay for a higher interest rate relative to one of their previous choices. To explore potential differences between individuals who made just one contradictory choice and more than one contradictory choices,

\footnotetext{
5 It is, of course, recognised that, in addition to an individual's discount rate, their decisions to pay on time may reflect their sense of duty or their strong desire to pay back the loan as quickly as possible.
} 
we classify them separately. Example choice trajectories from these subgroups are illustrated in Fig. 2c, d, respectively.

In this paper, we are interested in jointly modelling the factors that determine the choice trajectory as well as the sequence of choices. To begin with, let $g_{t_{n}}$ be an indicator variable equal to one when the sequence of choices made by individual $n$ matches choice trajectory $t$ and zero otherwise. Following from the discussion above, we have $T=5$ mutually exclusive choice trajectories and we assign $g_{1_{n}}$, $g_{2_{n}}, g_{3_{n}}, g_{4_{n}}$ and $g_{5_{n}}$ to represent the minimum delay, maximum delay, monotonically decreasing, one contradiction and more than one contradiction choice trajectories, respectively. We assume that the error terms are deviates from identically and independently extreme value distributions such that the likelihood that trajectory $t$ is exhibited by individual $n$ can be expressed as a multinomial logit:

$$
\operatorname{Pr}\left(g_{t_{n}}=1 \mid \alpha, \beta, \mathbf{z}_{n}\right)=\frac{\exp \left(\alpha_{t}+\beta_{t *} \mathbf{z}_{n}\right)}{\sum_{t=1}^{T} \exp \left(\alpha_{t}+\beta_{t *} \mathbf{z}_{n}\right)},
$$

where $\alpha$ is a constant vector with $T$ elements, $\beta$ is a $T \times K$ matrix, with $\beta_{t *}$ a row vector of $K$ unknown parameters to be estimated and $\mathbf{z}_{n}$ is a conforming column vector of $K$ regressors relating to individual $n$. For identification purposes, we normalise $\alpha_{1}$ and all elements of $\beta_{1 *}$ to zero. Therefore, the estimated coefficients will allow us to assess the effect that individual characteristics have on the likelihood of observing each choice trajectory.

Turning to modelling of the choices themselves, we begin with a discounted utility function (Samuelson 1937; Koopmans 1960; Cohen et al. 2016). Conditional on exhibiting trajectory $t$, we express the observable component of utility, $v$, for individual $n$ paying back the debt in month $m$ (where $m \in\{0,1, \ldots, 12\}$ ) in choice task $s$ (where $s \in\{1,2, \ldots, 7\}$ and each choice task has an unique interest rate) as follows:

$$
v_{t_{m s_{n}}}=B\left(1+\delta_{t_{n}}\right)^{m_{s} / 12},
$$

where $B$ is the amount borrowed (i.e., either $£ 500$ or $£ 5000$ ) depending on the treatment, and $\delta_{t_{n}}$ is the discount rate for individual $n$ conditional on exhibiting choice trajectory behaviour $t$. For $\delta_{t_{n}}$, given our interest in exploring the impact of individual characteristics on the discount rate, an exponential parameterisation is used:

$$
\delta_{t_{n}}=\exp \left(\gamma_{t}+\psi_{t *} \mathbf{z}_{n}\right) \text {. }
$$

where $\gamma_{t}$ is a constant, $\mathbf{z}_{n}$ is column vector of regressors, as above, and $\psi_{t *}$ is conformable row vector of unknown parameters to be estimated. Thus, depending on the observed sources of heterogeneity contained within $\mathbf{z}_{n}, \delta_{t_{n}}$ is individual-specific. Recall that total repayments, which we denote as $v_{m_{s}}$, were presented to participants and that these corresponded to the month of delay duration, $m$, and choice task, $s$. 
Given this, the net observable utility (i.e., net benefit), $v_{t_{m s_{n}}}^{*}$, for every alternative can be established by taking the difference between $v_{t_{m s_{n}}}$ and $v_{m_{s}}: 6$

$$
v_{t_{m s_{n}}}^{*}=v_{t_{m s_{n}}}-v_{m_{s}} \text {. }
$$

Assuming that the error terms are deviates from identically and independently extreme value distributions, and $\mathbf{y}_{n}=\left\{m_{1_{n}}, m_{2_{n}}, \ldots, m_{S_{n}}\right\}$ denotes the $S$ choices made by individual $n$, the probability of the sequence of choices, conditional on choice trajectory behaviour $t$, can be expressed as a product of conditional logits:

$$
\operatorname{Pr}\left(\mathbf{y}_{n} \mid t_{n}, \gamma, \psi, \mathbf{z}_{n}\right)=\prod_{s=1}^{S} \frac{\exp \left(v_{t_{m s_{n}}}^{*}\right)}{\sum_{m \in C_{t s_{n}}} \exp \left(v_{t_{m s_{n}}}^{*}\right)}
$$

where $C_{t s_{n}}$ is the consideration set of alternatives that is determined by choice trajectory $t$ and choices prior to task $s$. To elaborate, for the subset of individuals whose choices match minimum delay and maximum delay trajectories $C_{t s_{n}}$ contains only the first alternative and the last alternative, respectively. As a result, their choice probability is one. In contrast, for individuals identified as having made more than one contradictory choice, $C_{t s_{n}}$ contains all time delay options. However, for the monotonically decreasing choice trajectory we restrict the consideration set to not include any time delay option that is greater than the time delay they choose in the preceding choice task. Similarly for individuals whose trajectory includes one contradictory choice, but in this case the restricted consideration set only applies after the contradictory choice. Therefore, with $C_{t s_{n}}$, we map the decision-making process to the choice trajectory.

Under these assumptions, the full likelihood of the joint model for individual $n$ can be expressed as the expectation (over choice trajectories) of the trajectory-specific contributions:

$$
\operatorname{Pr}\left(g_{t_{n}}=1 \wedge \mathbf{y}_{t_{n}}\right)=\sum_{t=1}^{T} g_{t_{n}} \operatorname{Pr}\left(g_{t_{n}}=1 \mid \alpha, \beta, \mathbf{z}_{n}\right) \operatorname{Pr}\left(\mathbf{y}_{t_{n}} \mid g, \gamma, \psi, \mathbf{z}_{n}\right)
$$

\section{Results}

\section{Sample description by repayment choice trajectory}

To determine how repayment decisions vary across sociodemographic groups and treatments, the relative frequency of type of choice trajectory in Table 3 is compared. For treatment 1 ( $£ 500$ loan), four types of choice trajectory were apparent: minimum

\footnotetext{
${ }^{6}$ We introduce a scale parameter for the treatment where $B=£ 5000$, by dividing $v_{t_{m s_{n}}^{*}}$ by 10 to facilitate more straightforward comparison between treatments.
} 
Table 3 Breakdown of participants by choice trajectories (\%)

\begin{tabular}{|c|c|c|c|c|c|c|c|c|}
\hline & \multicolumn{8}{|l|}{ Treatment 1} \\
\hline & \multicolumn{2}{|c|}{ Minimum delay } & \multicolumn{2}{|c|}{$\begin{array}{l}\text { Monotonically } \\
\text { decreasing }\end{array}$} & \multicolumn{2}{|c|}{ One contradiction } & \multicolumn{2}{|c|}{$\begin{array}{l}\text { More than one } \\
\text { contradiction }\end{array}$} \\
\hline Female & \multicolumn{2}{|l|}{26.99} & \multicolumn{2}{|l|}{2.97} & \multicolumn{2}{|l|}{7.66} & \multicolumn{2}{|c|}{14.83} \\
\hline Male & \multicolumn{2}{|l|}{27.37} & \multicolumn{2}{|l|}{3.16} & \multicolumn{2}{|l|}{5.84} & \multicolumn{2}{|c|}{11.20} \\
\hline Aged 18-30 & \multicolumn{2}{|l|}{5.45} & \multicolumn{2}{|l|}{0.57} & \multicolumn{2}{|l|}{2.49} & \multicolumn{2}{|l|}{8.90} \\
\hline Aged $31-60$ & \multicolumn{2}{|l|}{29.28} & \multicolumn{2}{|l|}{4.02} & \multicolumn{2}{|l|}{8.71} & \multicolumn{2}{|c|}{15.02} \\
\hline Aged over 60 & \multicolumn{2}{|l|}{19.52} & \multicolumn{2}{|l|}{1.53} & \multicolumn{2}{|l|}{2.20} & \multicolumn{2}{|l|}{1.91} \\
\hline $\begin{array}{l}\text { Income below } \\
£ 15,000\end{array}$ & \multicolumn{2}{|l|}{9.09} & \multicolumn{2}{|l|}{1.24} & \multicolumn{2}{|l|}{3.73} & \multicolumn{2}{|l|}{4.98} \\
\hline $\begin{array}{l}\text { Income } £ 15,000 \text { - } \\
£ 29,999\end{array}$ & \multicolumn{2}{|l|}{15.79} & 2.01 & & 4.31 & & 7.94 & \\
\hline $\begin{array}{l}\text { Income } £ 30,000 \text { - } \\
£ 39,999\end{array}$ & 9.86 & & 0.96 & & 1.82 & & 3.92 & \\
\hline $\begin{array}{l}\text { Income above } \\
£ 40,000\end{array}$ & 14.35 & & 1.72 & & 2.97 & & 6.89 & \\
\hline $\begin{array}{l}\text { Income(prefer not } \\
\text { to say) }\end{array}$ & 5.26 & & 0.19 & & 0.67 & & 2.30 & \\
\hline Financially literate & 17.51 & & 1.53 & & 1.63 & & 2.97 & \\
\hline Financially illiterate & e 36.84 & & 4.59 & & 11.87 & & 23.06 & \\
\hline Ever miss payment & 6.70 & & 1.72 & & 3.92 & & 11.29 & \\
\hline Never miss payment & 47.66 & & 4.40 & & 9.57 & & 14.74 & \\
\hline Overall & 54.35 & & 6.12 & & 13.49 & & 26.03 & \\
\hline & Treatment 2 & & & & & & & \\
\hline & Minimum delay & & $\begin{array}{l}\text { o- } \\
\text { cally } \\
\text { easing }\end{array}$ & $\begin{array}{l}\text { One c } \\
\text { tion }\end{array}$ & ontradic- & $\begin{array}{l}\text { More } \\
\text { one co } \\
\text { tion }\end{array}$ & n & Maximum delay \\
\hline Female & 29.00 & 5.9 & & 3.03 & & 10.81 & & 1.42 \\
\hline Male & 29.57 & 5.2 & & 3.70 & & 9.95 & & 1.33 \\
\hline Aged 18-30 & 9.29 & 3.2 & & 2.27 & & 10.14 & & 0.85 \\
\hline Aged $31-60$ & 28.06 & 5.6 & & 2.94 & & 8.34 & & 1.61 \\
\hline Aged over 60 & 21.14 & 2.1 & & 1.52 & & 2.09 & & 0.28 \\
\hline $\begin{array}{l}\text { Income below } \\
£ 15,000\end{array}$ & 10.90 & 1.7 & & 1.14 & & 3.03 & & 0.47 \\
\hline $\begin{array}{l}\text { Income } £ 15,000 \text { - } \\
£ 29,999\end{array}$ & 16.49 & 3.7 & & 2.27 & & 7.87 & & 1.33 \\
\hline $\begin{array}{l}\text { Income } £ 30,000 \text { - } \\
£ 39,999\end{array}$ & 10.33 & 1.7 & & 0.85 & & 3.22 & & 0.19 \\
\hline $\begin{array}{l}\text { Income above } \\
£ 40,000\end{array}$ & 16.02 & 2.9 & & 1.90 & & 5.21 & & 0.47 \\
\hline $\begin{array}{l}\text { Income(prefer not } \\
\text { to say) }\end{array}$ & 4.83 & 1.0 & & 0.57 & & 1.42 & & 0.28 \\
\hline $\begin{array}{l}\text { Financially } \\
\text { literate }\end{array}$ & 15.17 & 2.1 & & 0.95 & & 1.80 & & 0.19 \\
\hline
\end{tabular}


Table 3 (continued)

\begin{tabular}{llllll}
\hline & \multicolumn{2}{l}{ Treatment 2 } & & \\
\cline { 2 - 6 } & Minimum delay & $\begin{array}{l}\text { Mono- } \\
\text { tonically } \\
\text { decreasing }\end{array}$ & $\begin{array}{l}\text { One contradic- } \\
\text { tion }\end{array}$ & $\begin{array}{l}\text { More than } \\
\text { one contradic- } \\
\text { tion }\end{array}$ & Maximum delay \\
\hline $\begin{array}{c}\text { Financially } \\
\text { illiterate }\end{array}$ & 43.41 & 9.00 & 5.78 & 18.96 & 2.56 \\
$\begin{array}{c}\text { Ever miss } \\
\text { payment }\end{array}$ & 8.06 & 2.84 & 2.65 & 9.29 & 1.04 \\
$\begin{array}{c}\text { Never miss } \\
\text { payment }\end{array}$ & 50.52 & 8.34 & 4.08 & 11.47 & 1.71 \\
\begin{tabular}{c} 
Overall \\
\hline
\end{tabular} & 58.58 & 11.18 & 6.73 & 20.76 & 2.75 \\
\hline
\end{tabular}

delay, monotonically decreasing, one contradiction, and more than one contradiction. For treatment 2 ( $£ 5000$ ), an additional choice trajectory was observed-maximum delay. In both treatments, more than half of the participants elected to take the minimum delay option. In treatment 2 more participants exhibited minimum delay and monotonically decreasing choice trajectories, and less exhibited contradictory choice trajectories. Choice trajectories for both treatments are depicted in Fig. 3, in which repayment decisions are demonstrated by mean values and confidence intervals for each interest rate level.

In treatment $1,54 \%$ of participants chose to repay the loan with minimum delay; $6 \%$ of them manifested a monotonically decreasing choice trajectory; other participants exhibited contradictory choice trajectories (13\% made one contradictory choice and 26\% made more than one contradictory choice). Participants aged 18-60 were more likely to exhibit minimum delay trajectory, followed by a contradictory choice trajectory. Participants aged over 60 years were more likely to exhibit a minimum delay trajectory than a monotonically decreasing or contradiction trajectory, as were financially literate participants. Participants who are financially illiterate are also more likely to manifest a minimum delay trajectory, which suggests that the way to present borrowing costs in our experiment is good at communicating financial costs to some financially illiterate participants. Apart from those who chose minimum delay, most other financially illiterate participants manifested contradictory (rarely monotonically decreasing) choice trajectories.

In treatment $2,58 \%$ of participants chose minimum delay; $11 \%$ exhibited a monotonically decreasing trajectory, $7 \%$ exhibited one contradiction, and $21 \%$ more than one contradiction. This suggests that an increase in loan size and borrowing cost resulted in participants investing more effort in decision making, and making fewer contradictory choices. A further $3 \%$ of participants also chose the maximum delay option, preferring to extend repayment to the limit with an increased loan size. Within each demographic subset a high proportion of participants took minimum delay. Fewer participants aged 31-60 years manifested a choice trajectory including a contradiction, indicating greater effort in the decision-making process. More financially illiterate participants also chose minimum delay. We also visually present 

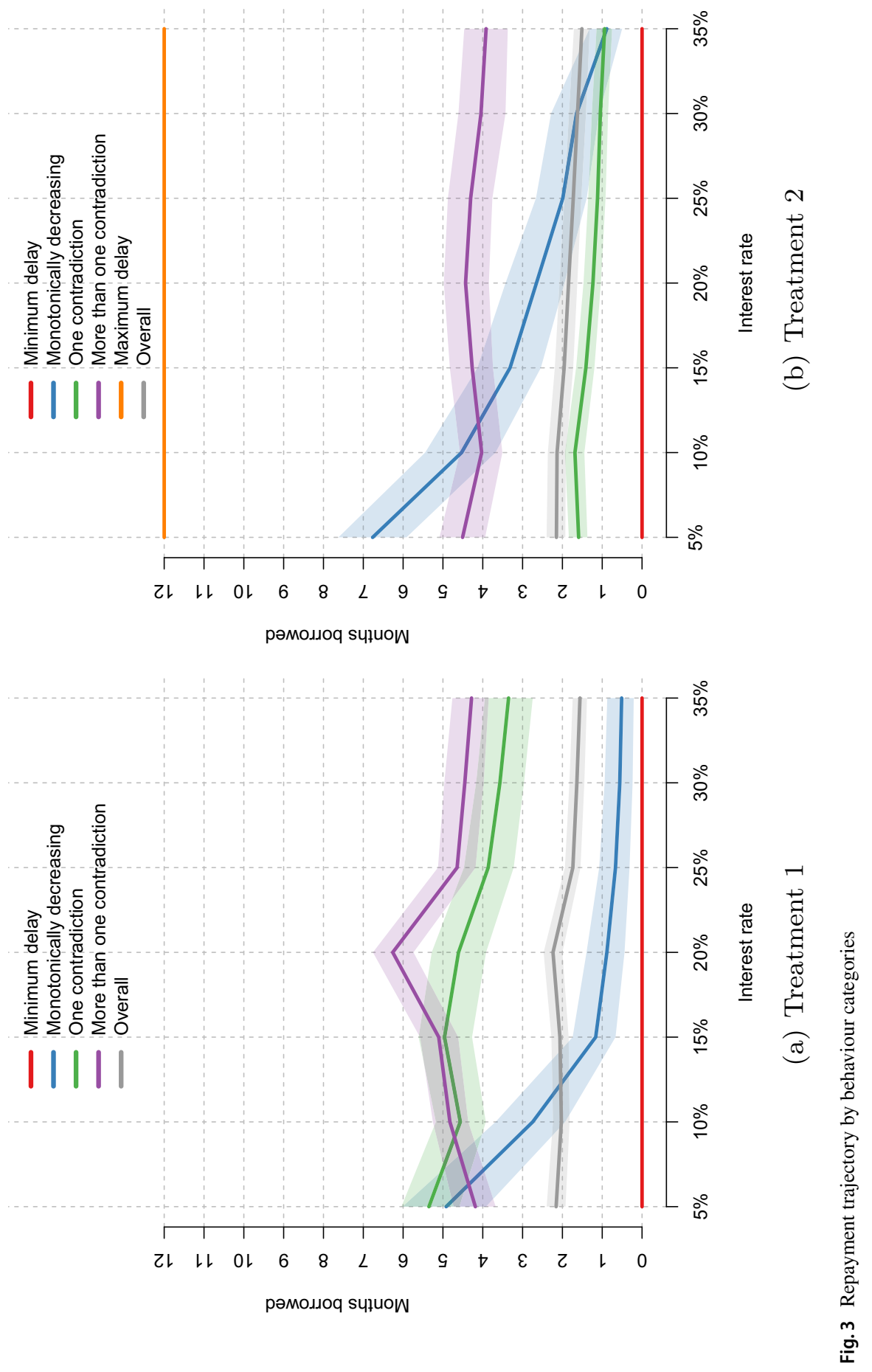
the choice trajectories for both treatments in Figure 2, in which repayment decisions are demonstrated by the means and confidence intervals at the interest rate levels. Treatment 1 participants on average prefer to delay repayment for 2 months at all interest rate levels. Those who exhibit monotonically decreasing trajectories delay repayment for an average of 5 months at an interest rate of 5\%, but shorten this delay to about 1 month at interest rates exceeding 15\%. Participants who present both contradictory choices trajectories (green and purple patterns) generally delay repayment longer. In the choice trajectory with one contradiction, the preferred delay was around 5 months at interest rates of 5\%-15\%, but decreased at interest rates exceeding $15 \%$. A contradiction of this trajectory appeared when the interest rate increased from $10 \%$ to $15 \%$. The trajectory with more than one contradiction manifested the longest delay across all trajectories when interest rates exceed $10 \%$, for which the delay increased as interest rates rose from 5\% to $20 \%$. Of all trajectories, that with more than one contradiction was the most inconsistent with normative expectations, possibly because participants had difficulty making repayment decisions (comparing or calculating borrowing costs); this trajectory also had the highest proportion of participants who missed payments and were financially illiterate across other trajectories .

In treatment 2, participants on average would delay the repayment around 2 months at all interest levels when the borrowing amount increased to $£ 5000$. Although the costs of extending repayment are higher than for treatment 1, contrary to expectations participants extended shorten the extension term, and participants manifesting a monotonically decreasing choice trajectory (blue pattern) extended repayment. Less contradiction is also apparent in the two contradictory trajectories (green and purple patterns) compared to treatment 1, with these two trajectories also having shorter delay terms. Results suggest that participants invest effort in comparing borrowing costs when decision-making, and to prefer repaying a loan quicker at an increased loan size.

\section{Estimation Results}

Model estimation results for treatment 1 are presented in Table 4a. Gender does not play a significant role in the classification of all choice trajectories, and age and financial literacy do not seem to significantly affect the classification of the monotonically decreasing trajectory. For participants who follow a monotonically decreasing choice trajectory, a significant effect is apparent between financial literacy on estimation of discount rate (Table 4a). Trajectories with contradictions are less likely to occur in participants aged $60+$ years who are financially literate, compared to those who make consistent choices (i.e. monotonically decreasing). The significance of covariates associated with participant-specific characteristics indicates that the first component of the model explains heterogeneity of repayment choice trajectories well. By observing coefficients associated with discount rate in the second component, we find that trajectory-specific constants $(\gamma \mathrm{s})$ are statistically significant across choice trajectories, suggesting that estimated discount rates are significant. However, sociodemographic characteristics included 
Table 4 Model estimation results

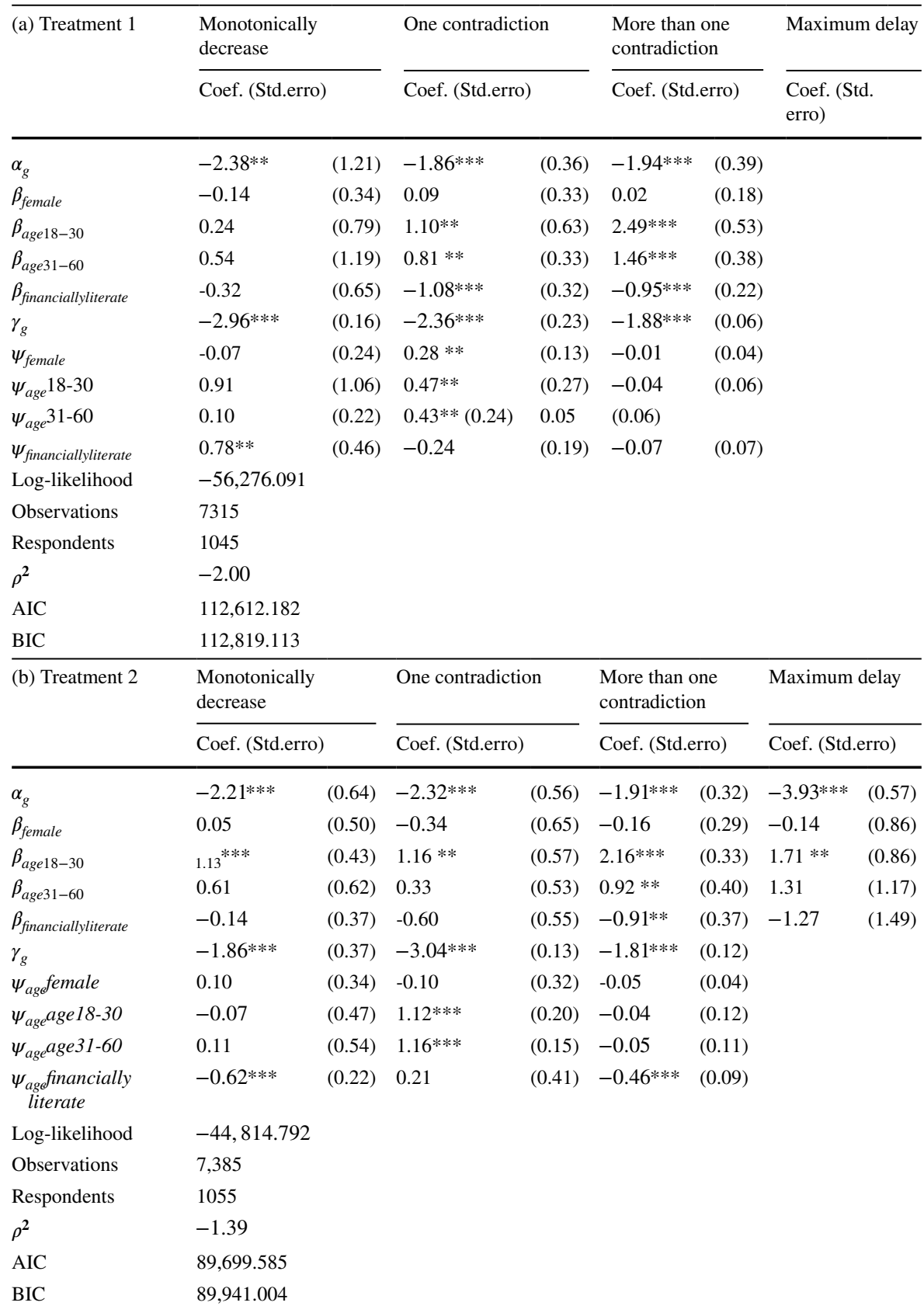

All standard errors (in parentheses) are robust and clustered at the participant level. *** and*** indicate statistical significance at the 10,5 and 1 percent levels, respectively, using the $p$ value of a one-sided test 
in analyses significantly impact estimated discount rate in the trajectory with one contradiction only. More specifically, female participants had a higher discount rate than males; participants less than 60 years also tended to have higher discount rates than those aged $60+$. These differences might be driven by different purchase behaviours of participants in these two age groups. Financial literacy significantly impacted the monotonically decreasing trajectory, indicating that these choice makers would borrow money at a higher discount rate than financially illiterate participants. As choice trajectories are subject to different scaling in our models, we refrain from further comparisons of trajectory-specific estimates.

In treatment 2 (Table $4 \mathrm{~b}$ ) the maximum delay choice trajectory becomes apparent. ${ }^{7}$ No significant effect of gender on the classification of any trajectory is apparent. However, participants associated with the four choice trajectories are highly likely to be aged between 18 and 30. Financial literacy significantly affects the composition of the trajectory with more than one contradiction, with those who tend to make more than one contradictory choice also tending to be financially illiterate. Financial literacy does not significantly impact the trajectories in which participants make no or only one contradiction.

There is no gender effect on discount rate estimates. Among participants who made only one contradictory choice, age significantly affected discount rate; participants aged over 60 had a lower discount rate than all others. Financial literacy has a significant negative effect on discount rate estimates for both the monotonically decreasing (consistent) choice trajectory and the trajectory with more than one contradiction.

\section{Estimates of Choice Probability and Discount Rate}

To compare trajectories, choice probabilities and discount rates conditional on specific choice trajectories and socioeconomic factors are estimated based on the estimated results with 10,000 simulated draws. Expected choice probability values and discount rate values (and their 95\% confidence intervals) are presented in Table 5.

\section{Treatment 1}

Treatment 1 choice probability confidence intervals (Table 5a) permit differences in sociodemographic subsets across choice trajectories to be examined, although mean probabilities conditional on choice trajectories are equivalent to the relative frequencies. Male, elderly (over 60 years) and financially literate participants are more likely to opt for minimum delay repayment than other participants, with the probability a participant exhibiting this trajectory differing significantly across age ranges: $74 \%$ for those aged over $60,51 \%$ for those aged $31-60$, and $32 \%$ for those

\footnotetext{
7 We exclude the estimated discount rate for this trajectory in our model. Because participants exhibiting this trajectory chose maximum delay in a scenario with an interest rate of $35 \%$, we regard their discount rate to be at least $35 \%$.
} 


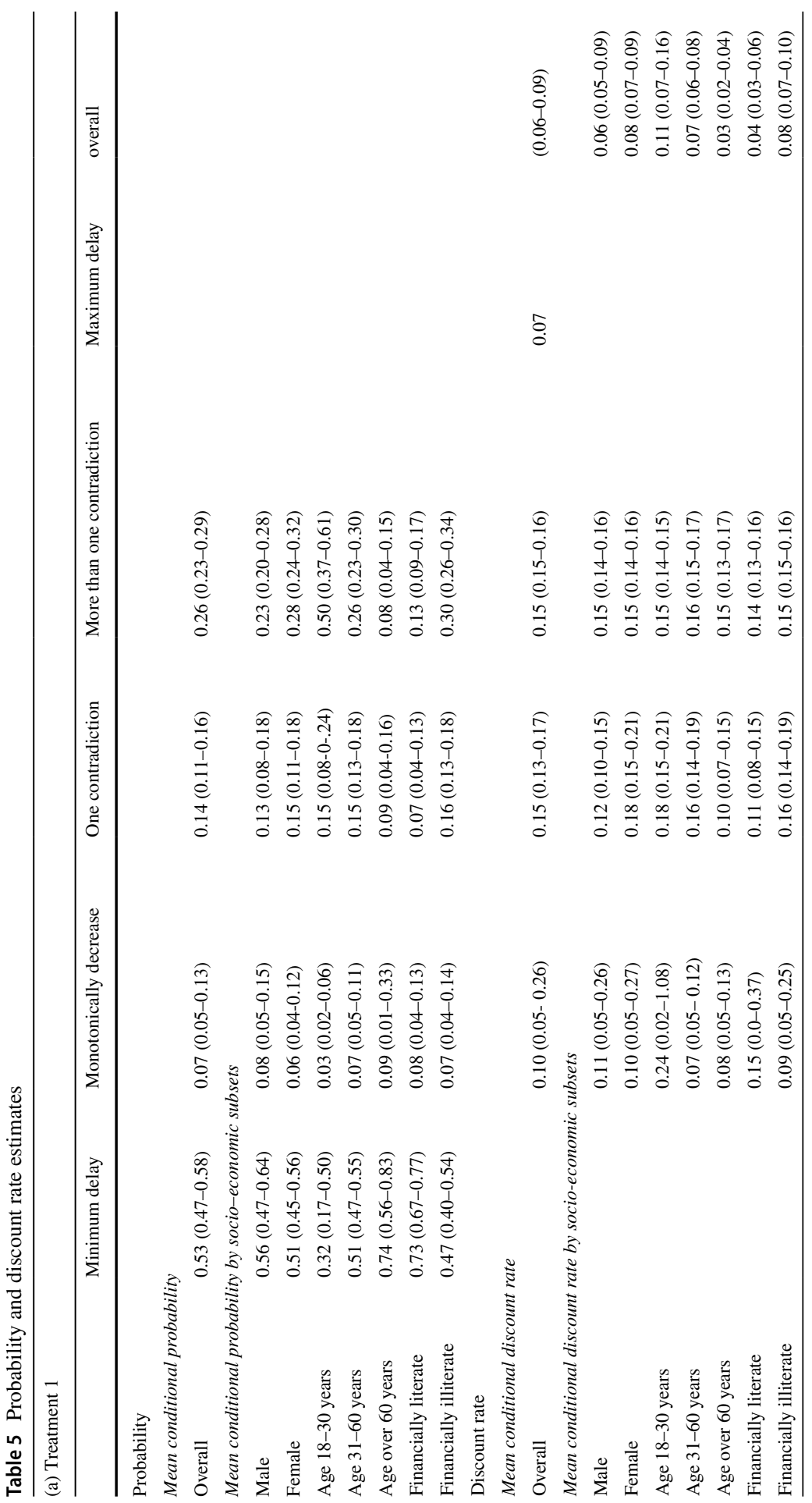




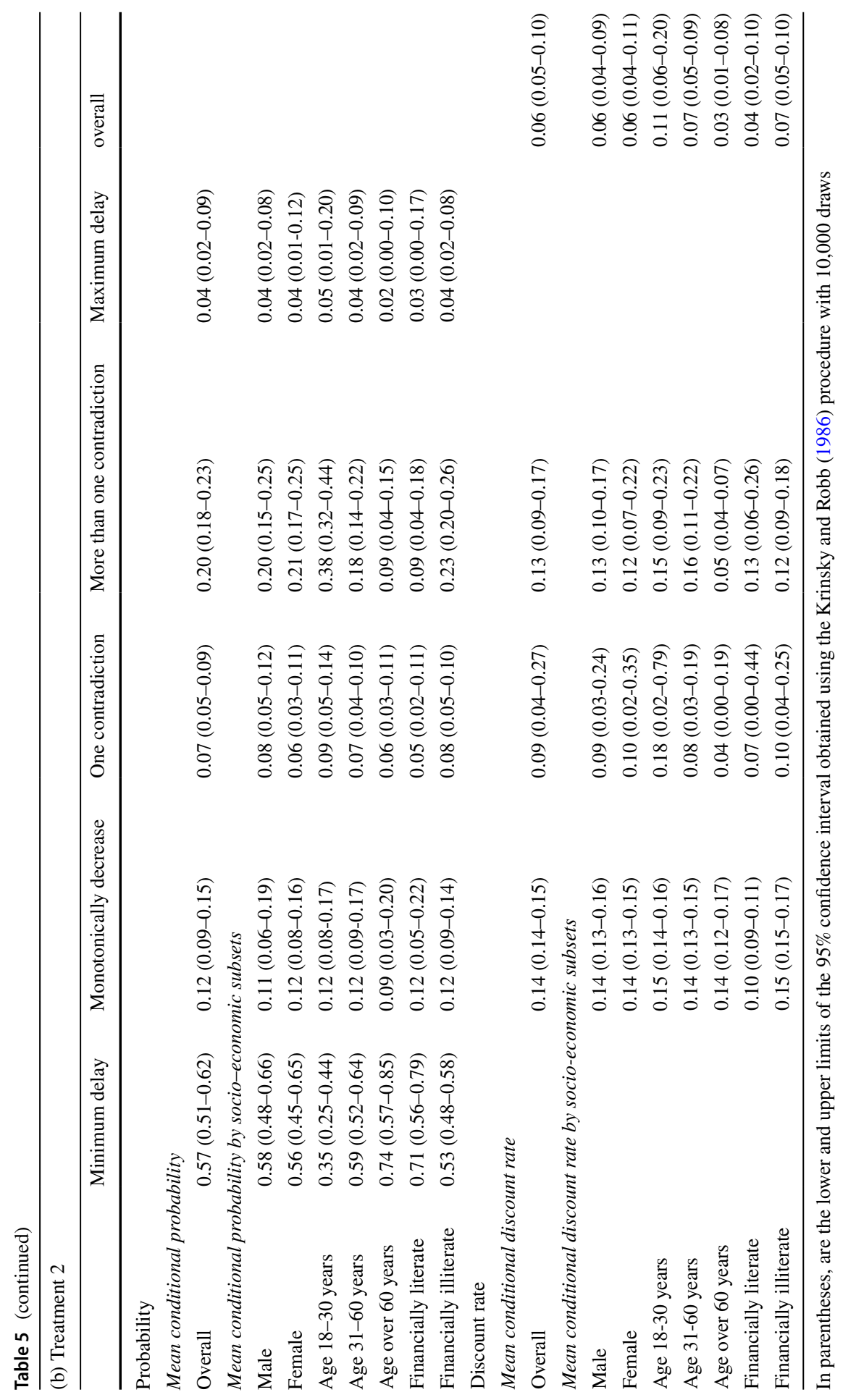


aged 18-30. This same pattern is observed between financially literate and illiterate subsets. Mean choice probabilities of participants exhibiting a monotonically decreasing choice trajectory do not significantly differ between sociodemographic groups. The probability of a financially illiterate female less than 60 years age following a trajectory with more than one contradiction is higher than it is for following a trajectory with a single contradiction.

The average discount rates in treatment 1 is 0.07 , which is heavily influenced by a discount rate of 0 for minimum delay (53\% of participants). The second lowest discount rate $(0.10)$ occurs among participants manifesting a monotonically decreasing choice trajectory, followed by those manifesting choice trajectories with one or multiple contradictions (0.15). Confidence intervals in the monotonically decreasing trajectory have wider intervals, indicating greater variability in repayment preferences among participants. For trajectories with contradictions, no significant differences in average discount rates among sociodemographic groups are apparent, except for participants between 18 and 30, for which the discount rate in the trajectory with one contradiction $(0.18)$ is significantly higher than that for more than one contradiction $(0.15)$. The discount rate for the same age category is much higher in the monotonically decreasing trajectory $(0.24)$.

\section{Treatment 2}

Inspecting the probability of Treatment 2 (Table 5b), no significant differences in probabilities of exhibiting choice trajectories between males and females are apparent. Significant differences are apparent for different age-range groups in minimum delay and more than one contradictory choices, with participants aged over 60 and those that are financially literate more likely to choose minimum delay, while those between 18-30 years age and the financially illiterate more prone to making contradictory choices. Compared to Treatment 1 , as the probability of exhibiting a monotonically decreasing choice trajectory exhibited by sociodemographic subset groups increases, that of exhibiting a contradictory choice trajectory decreases. This is most marked among those aged between 18 and 30 and the financially illiterate who make more than one choice contradiction, indicating that these participants increased invested in repayment decisions as the loan size increased.

The average discount rate in treatment 2 is 0.06 , driven by a high proportion of minimum delay choices. The maximum delay discount rate (0.35) is affected by the experiment interest rate ceiling. There are no significant differences in discount rates across choice trajectories.

Comparing the discount rates between treatment 1 and treatment 2, the monotonically decreasing trajectory in treatment 2 has a higher average discount rate (0.14) than in treatment 1 , suggesting that participants who make consistent repayment decisions would pay more borrowing costs to extend a repayment when the loan size increased to $£ 5000$. Discount rates for contradictory choice trajectories are also lower and have wider confidence intervals than in treatment 1 , indicating that (on average) these participants prefer repaying a loan with a shorter term of extension, but that there was greater variation in their preferences. 
There was no significant difference in discount rates for males and females. Participants aged between 18 and 60 and those who are financially illiterate generally had higher discount rates than those aged over 60 and who are financially literate. For the monotonically decreasing trajectory, a significant difference in discount rate was observed only between financially literate and illiterate subsets. The lower discount rate of financially literate participants is consistent with our expectation that these participants would prefer a longer extension term. Narrower confidence intervals for socio-demographic subsets indicate reduced variability in repayment preferences than for treatment 1 , indicating less variability for consistent choice makers in their repayment decisions for a greater loan size. In instances of one contradiction, the discount rate of participants aged 18-30 years is significantly higher than that for participants aged over 60 , and the wider confidence intervals indicate greater variability in repayment preferences. Significant differences in discount rate for a given age cohort between treatments are also apparent when a participant makes more than one contradictory choice. Because no difference was apparent between socio-demographic subsets where more than one contradiction in choice was made in treatment 1 , the difference in discount rates between treatments suggests that participants had different time preferences as their loan size increased, with heterogeneity in repayment preference probably attributable to age.

\section{Discussion: Comparison Against the Past Studies}

The average annual discount rate (depending on loan size) of about 6-7\% is strongly influenced by discount rates of $0 \%$ from the $53 \%$ of participants who elected to repay a loan with minimum delay. The discount rate for participants who otherwise preferred to delay repayment ranged about 9-15\%. Discount rates vary across choice trajectories, socioeconomic subsets, and loan sizes. We consider our estimation of discount rates to be reasonable because rates were similar to (then) market loan interest rates and credit card annual percentage rates, were within previously reported ranges, and related repayment and discounting behaviours have been identified in previous studies.

Previously estimated discount rates are variable because of non-standardised data collection methods, and differing study contexts. Most research effort has focussed on monetary rewards (MEL analyses). In analyses using a Multiple Price List method, a discount rate is estimated with linear utility and elicited at a switching point $^{8}$, yielding anomalously high discount rates which can exceed hundreds (e.g., 102.2\%, Andreoni et al. (2015)); discount rates estimated using a utility adjusted for curvature are lower than those estimated using a linear utility. Using a Double Multiple Price List method, the average discount rate of $10 \%$ of Andersen et al. (2008) resembles ours. Another method (Convex Time Budget) involving adjustment of the

\footnotetext{
8 The switching points in 'sooner or later payment' lists indicate when a participant considers sooner (at time point $t$ ) payments do not differ to later (at time point $t+k$ ) payments, $U\left(c_{t}\right) \approx \delta^{k} U\left(c_{t+k}\right)$. The discount rate is calculated as $\frac{1}{\left(c_{t} / c_{t+k}\right)^{1 / k}}-1$.
} 
curvature of utility reported by Andreoni and Sprenger (2012) generated average discount rates between $25 \%$ and $35 \%$. In a comparison of these methods Andreoni et al. (2015) suggested that the predictive power of the Convex Time Budget was greater because it allowed both linear and non-linear utilities. In a review of literature regarding measurement of discount rate using money outside of the controlled laboratory environment, Ericson and Laibson (2019) found most studies reported discount rates between about 10\% and 20\% (although Hausman (1979) reported an average discount rate of $20 \%$ when looking at individual purchase behaviour, in which trade-off between capital costs and operating costs for the appliances was studied). Our average discount rates, even after excluding minimum delay choice makers, are relatively low. Unlike monetary rewards, outcomes in repayment decisions (paying back borrowing costs) might be painful for some people (Fishburn and Rubinstein 1982), explaining our low discount rate estimates.

Our results are similar to those of previous MEL studies. These behaviours are associated with present or future biases, consistent response, and reversal choices. A present bias indicates that individuals are more likely to overestimate immediate and under-estimate future rewards, and a future bias indicates the opposite (Takeuchi 2011). The response associated with these biases is one of choosing an earlier or later reward (Andreoni and Sprenger 2012), with roughly 50\% of participant responses selecting an earlier payment. Maximum and minimum delay behaviours are associated with present and future biases. Consistent responses in MEL studies are that participants first choose the later reward, but switch to an earlier reward when the extra amount in the latter option is lower than their discount rate. Similar to consistent responses, in our study participants who exhibit a monotonically decreasing choice trajectory tend to repay a loan quicker when the borrowing cost is higher than their discount rate. Reversal choices in MEL studies are the responses when individuals irregularly switch between sooner or later options. A high proportion of participants in previous MEL studies have made reversal choices (e.g., 13\% Holt and Laury 2002; $21 \%$ Anderson and Mellor 2008). Choice trajectories with contradictions are similar to reversal choices, and participants who exhibit them have no stable preference for repaying a loan sooner or later. This anomaly is explained by Ericson and Laibson (2019) as a consequence of dynamically consistent and inconsistent preferences mutually affecting a person's decision, with both present-bias and temptation affecting a response.

A size effect is apparent, with individual discount rate falling as the reward size increases. This phenomenon was explained by Thaler (1981) with the concept of self-control-that waiting for a larger payment requires effort. This effect has been observed in studies of time preference using multiple price list, double multiple price list (Andersen et al. 2006; Andreoni et al. 2015), and matching (Benhabib et al. 2010) methods. While participants who borrowed $£ 500$ tended to have slightly higher average discount rates than those who borrowed $£ 5000$, this difference was not significant.

While our reported effects of socio-economic variables on time preference are mostly consistent with the literature, we found no gender effect in repayment decisions and discount rate, contrary to Van Praag and Booij (2003) who reported males considered the future more than females in the decision-making process. Younger individuals are more likely to be impatient and lack self-control, contributing to a 
high discount rate (e.g., Read and Read 2004; Harrison et al. 2002). Financially literate individuals are also more future oriented (Meier and Sprenger 2013) and have lower discount rates. It is worth noting that our results are, of course, empirical. The manner in which we elicit time preferences is unique, which makes it difficult to compare against previous studies. Nevertheless, the fact that the main results are broadly in line with earlier studies provides some reassurance on the external validity of our findings.

\section{Conclusion}

We sought to understand consumers' decision-making and time preferences in the context of loan repayments in the UK, and to ascertain discount rates using a stated preference approach. To achieve this, we designed a hypothetical experiment in which we applied a novel data collection method most similar to the MEL technique to elicit discount rate. Insights into repayment decisions and discount rates are made using choice modelling, with a joint modelling framework; we also explain heterogeneity in choice trajectories, and explore the impacts of socioeconomic factors on participant time preferences. Persons aged 60 and financially literate tended to minimally delay repayment and have a consistent choice trajectory, while participants aged 18-30 who are financially less literate tended to make more contradiction choices and have a higher discount rate. To ascertain the effect of loan size on repayment behaviours, we established two treatments-one offered a loan of $£ 500$ and the other $£ 5000$. Increasing loan size resulted in more participants electing to minimally delay repayment and make more consistent choices in different repayment scenarios, and fewer contradictory choice trajectories. Average discount rate decreases because more financially illiterate participants and those aged 18-30 prefer minimum delay choices and had a lower discount rate, while a small proportion of participants preferred to extend repayment, and had a higher discount rate.

Our experiment is based upon participant choice in various hypothetical repayment scenarios. This may generate problems associated with hypothetical responses (e.g., failure to connect with their personal financial circumstances in the real world). We notice that there will be variation in the findings if repayment behaviours would have been studied using a revealed preference approach. As repayment behaviours can be influenced by many factors associated with consumer financial situations (e.g., consumer spending), this kind of data are available on the market, using revealed preference data can produce comprehensive results. We believe that the use of hypothetical data generates improved results in a controlled experimental environment. While consumers commonly deal with more than one loan or credit product (e.g., having more than one credit card), we do not address this in our research; further research is warranted to identify more comprehensive repayment profiles, such as how individuals make repayment decisions when faced with more than one loan. Additionally, a not-inconsequential proportion of consumers who make contradictory choices and/or delay repayment to the maximum permissible time are highly likely to be financially constrained. Further research on factors that contribute to the making of contradictory choices would also be valuable. 
Our insights into how consumers make repayment decisions (e.g., exhibiting choice trajectories, discount rates) contribute to an improved understanding of consumer repayment behaviours, preferences, and their predictions. Ultimately, information of this nature will assist policy-makers and financial institutions predict consumers repayment behaviours, i.e., given the characterisation of consumers, the repayment choice trajectories under different interest rate can be predicted. From financial institutions' point of view, predictions on consumers' repayment behaviours would be helpful to control the amount of borrowing to prevent consumers' over-indebtedness. Policy makers can implement appropriate strategies to the consumer groups who are more likely to make improper consumer repayment decisions to mitigate their debt issues.

Availability of data and material Available upon request from the corresponding author.

\section{Declarations}

Code availability Available upon request from the corresponding author.

Ethics approval Ethics approval was obtained from the Ethics Committee of the corresponding author's institution.

Consent to participate Consent was obtained from the study participants.

Open Access This article is licensed under a Creative Commons Attribution 4.0 International License, which permits use, sharing, adaptation, distribution and reproduction in any medium or format, as long as you give appropriate credit to the original author(s) and the source, provide a link to the Creative Commons licence, and indicate if changes were made. The images or other third party material in this article are included in the article's Creative Commons licence, unless indicated otherwise in a credit line to the material. If material is not included in the article's Creative Commons licence and your intended use is not permitted by statutory regulation or exceeds the permitted use, you will need to obtain permission directly from the copyright holder. To view a copy of this licence, visit http://creativecommons.org/licen ses/by/4.0/.

\section{References}

Andersen, S., G.W. Harrison, M.I. Lau, and E.E. Rutström. 2006. Elicitation using multiple price list formats. Experimental Economics 9 (4): 383-405.

Andersen, S., G.W. Harrison, M.I. Lau, and E.E. Rutström. 2008. Eliciting Risk and Time Preferences. Econometrica 76 (3): 583-618.

Anderson, L.R., and J.M. Mellor. 2008. Predicting health behaviors with an experimental measure of risk preference. Journal of Health Economics 27 (5): 1260-1274.

Andreoni, J., and C. Sprenger. 2012. Estimating time preferences from convex budgets. American Economic Review 102 (7): 3333-56.

Andreoni, J., M.A. Kuhn, and C. Sprenger. 2015. Measuring time preferences: A comparison of experimental methods. Journal of Economic Behavior\&amp; Organization 116: 451-464.

Benartzi, S., and R.H. Thaler. 1995. Myopic loss aversion and the equity premium puzzle. The Quarterly Journal of Economics 110 (1): 73-92.

Benhabib, J., A. Bisin, and A. Schotter. 2010. Present-bias, quasi-hyperbolic discounting, and fixed costs. Games and Economic Behavior 69 (2): 205-223. 
Berns, G.S., D. Laibson, and G. Loewenstein. 2007. Intertemporal choice-toward an integrative framework. Trends in Cognitive Sciences 11 (11): 482-488.

Cohen, J. D., K. M. Ericson, D. Laibson, and J. M. White. 2016. Measuring time preferences (No. w22455). National Bureau of Economic Research.

Coller, M., and M.B. Williams. 1999. Eliciting individual discount rates. Experimental Economics 2 (2): $107-127$.

Ericson, K. M., and D. Laibson. 2019. Intertemporal choice. In Handbook of Behavioral Economics: Applications and Foundations 1, Vol. 2, 1-67. North-Holland.

Fishburn, P. C., and A. Rubinstein. 1982. Time preference. International Economic Review 677-694.

Frederick, S., G. Loewenstein, and T. O'donoghue. 2002. Time discounting and time preference: A critical review. Journal of Economic Literature 40 (2): 351-401.

Financial Conduct Authority. 2016. Credit card market study: further analysis. https://www.fca.org.uk/ publication/market-studies.

Financial Conduct Authority. 2019. Consumer credit high cost short term credit lending data.https:// www.fca.org.uk/data.

Financial Conduct Authority. 2020. Helping customers in persistent debt. https://www.fca.org.uk/publication

Gathergood, J., N. Mahoney, N. Stewart, and J. Weber. 2019. How do individuals repay their debt? The balance-matching heuristic. American Economic Review 109 (3): 844-75.

Hardisty, D.J., K.C. Appelt, and E.U. Weber. 2013. Good or bad, we want it now: Fixed-cost present bias for gains and losses explains magnitude asymmetries in intertemporal choice. Journal of Behavioral Decision Making 26 (4): 348-361.

Harrison, G.W., M.I. Lau, and M.B. Williams. 2002. Estimating individual discount rates in Denmark: A field experiment. American Economic Review 92 (5): 1606-1617.

Hausman, J.A. 1979. Individual Discount Rates and the Purchase and Utilization of Energy-Using Durables. The Bell Journal of Economics 10 (1): 33-54.

Holt, C.A., and S.K. Laury. 2002. Risk aversion and incentive effects. American Economic Review 92 (5): 1644-1655.

INFE, O. 2011. Measuring financial literacy: Questionnaire and guidance notes for conducting an internationally comparable survey of financial literacy. https://www.oecd.org/finance.

Krinsky, I., and A. L. Robb. 1986. On approximating the statistical properties of elasticities. The Review of Economics and Statistics 715-719.

Koopmans, T. C. 1960. Stationary ordinal utility and impatience. Econometrica: Journal of the Econometric Society 287-309.

Lilly, C. 2020. UK credit card statistics 2020. https://www.finder.com/uk/credit-card-statistics.

Lusardi, A., and P. Tufano. 2015. Debt literacy, financial experiences, and overindebtedness. Journal of Pension Economics\&amp; Finance 14 (4): 332-368.

Meier, S., and C.D. Sprenger. 2013. Discounting financial literacy: Time preferences and participation in financial education programs. Journal of Economic Behavior\&amp; Organization 95: 159-174.

Ponce, A., E. Seira, and G. Zamarripa. 2017. Borrowing on the wrong credit card? Evidence from Mexico. American Economic Review 107 (4): 1335-61.

Read, D. 2004. Intertemporal choice. In Blackwell Handbook of Judgement and Decision Making, 424-443.

Read, D., and N.L. Read. 2004. Time discounting over the lifespan. Organizational Behavior and Human Decision Processes 94 (1): 22-32.

Samuelson, P.A. 1937. A note on measurement of utility. The Review of Economic Studies 4 (2): 155-161.

Shui, H., and L. M. Ausubel. 2004, May. Time inconsistency in the credit card market. In 14th Annual Utah Winter Finance Conference.

Takeuchi, K. 2011. Non-parametric test of time consistency: Present bias and future bias. Games and Economic Behavior 71 (2): 456-478.

Thaler, R. 1981. Some empirical evidence on dynamic inconsistency. Economics Letters 8 (3): 201-207.

Van Praag, B. M., and A. S. Booij. 2003. Risk aversion and the subjective time discount rate: A joint approach.

Ventura, L. 2003. Direct measures of time preference. The Economics and Social Review 34 (3): 293-310.

Publisher's Note Springer Nature remains neutral with regard to jurisdictional claims in published maps and institutional affiliations. 